\title{
The influence of nanostructure on the mechanical properties of 3D printed
} polylactide/nanoclay composites

\author{
Antigoni Paspali ${ }^{\mathrm{a}}$, Yuqing Bao ${ }^{\mathrm{a}, *}$, David T. Gawne ${ }^{\mathrm{a}}$, Frederik Piestert ${ }^{\mathrm{b}}$, Sebastian Reinelt ${ }^{\mathrm{b}}$ \\ ${ }^{a}$ School of Engineering, London South Bank University, 103 Borough Rd, London SE1 OAA, UK \\ ${ }^{b}$ BYK-Chemie GmbH, Abelstraße 45, 46483 Wesel, Germany \\ *Corresponding author, e-mail address: baoy@lsbu.ac.uk
}

\begin{abstract}
An obstacle for wider application of 3D printed parts is their inferior mechanical performance compared with those from conventional fabrication. This research aims to overcome this deficiency by developing nanostructured PLA/clay composite filaments that are 3D printable by the FFF technique, investigating the effect of filament composition on mechanical properties, and correlating it with the extent of intercalation of different types of clay. The results showed the addition of $5 \mathrm{wt} \%$ organomodified clay to PLA raised the elastic and flexural modulus by $10 \%$ and $14 \%$ respectively. Einstein's composite theory did not hold for the PLA/organoclay composites but the Halpin-Tsai model was successful in interpreting the measured moduli of the organoclays. The model also showed that increasing the clay intercalation was much more effective than raising the total clay content.
\end{abstract}

\section{Keywords}

A. Polymer-matrix composites (PMCs), A. Nano-structures, B. Mechanical properties, C. Computational modelling, 3D printing

\section{Introduction}

3D printing is an emerging transformational technology with considerable potential in diverse fields, including medical, pharmaceutical, automotive and aerospace field. Fused filament fabrication (FFF) is one of the most widely employed techniques in 3D printing, in part due to the success of the Replicating Rapid Prototyper (RepRapPro) project and the open-source movement [1]. FFF is based on fused deposition modeling, originally developed by Stratasys Inc. The FFF systems can be integrated with computer-aided design (CAD) suites and deliver products of intricate geometrical complexity within one fabrication step. These systems are inexpensive to maintain and are office-compatible since they involve limited or no use of hazardous chemicals.

FFF produces solid components or prototypes by the selective deposition of melt-extruded thermoplastic feedstock filaments on top of a building platform, following digitally generated tool paths [2]. The extruded polymer beads fuse with the underlying beads and solidify rapidly [3] to form 3D objects that ultimately consist of consecutive stacked layers of bonded polymer beads. Despite the popularity of the FFF and its ease of use, a series of limitations inhibits its potential as a sustainable alternative to traditional manufacturing methods. Studies on acrylonitrile butadiene styrene (ABS) [4-6], polypropylene [7] and polyether-ether-ketone [8] have revealed that the mechanical properties of $3 \mathrm{D}$ printed parts are inferior to the properties of their conventionally fabricated counterparts, due to poor compaction and the inherent air voids within the printed solid.

A possible approach for tailoring the properties of printing materials for FFF and expanding the range of their applications is by the addition of organomodified nanoclays to the polymer feedstock, in order to obtain polymer/clay composite filaments. Polymer/clay composites are expected to exhibit improved properties relative to those of the polymer matrix, at low loading levels [9-11], of which mechanical reinforcement is the most pronounced. The incorporation of nanoclays in the polymer feedstock filament is however associated with 
processing and fabrication challenges, including a high melt viscosity of the feedstock filament, to the detriment of its processibility and the formation of printed objects [2].

To date, there has been only limited research in the incorporation of polymer/clay composites in FFF [1116] that has shown improved properties, with the majority of the published work focusing on ABS/clay printed composites [11-13]. Along with ABS, PLA is one of the most used materials in filament compounding, in terms of market value and volume [17]. It is a renewable, biocompatible, and environmentally degradable polymer, which exhibits higher stiffness and strength than the petrochemically derived ABS. The focus of this study is to develop PLA/clay nanocomposite filaments that are printable by the FFF technique; to investigate the effect of the filament composition on the mechanical properties of the printed samples and correlate them with the extent of intercalation of different types of clays.

\section{Experimental details}

\subsection{Raw materials and filament preparation}

The pristine polymer utilised was PLA (grade: IngeoTM Biopolymer 2003D, NatureWorks). Three nanoclays from BYK-Chemie were employed in the investigation: Cloisite ${ }^{\circledR} 5$ (Clo5), Cloisite ${ }^{\circledR 20}$ (Clo20) and Cloisite ${ }^{\circledR} 116$ (Clo116). Both Clo5 and Clo20 are sodium bentonite clays organically modified (organoclays) with bis (hydrogenated tallow alkyl) dimethyl salt, but with different average particle size and d-spacing (Table 1). Clo116 is naturally sourced sodium bentonite. The typical properties of all raw materials are listed in Table 1. The raw materials were processed at BYK-Chemie.

Table 1: Typical properties of PLA Ingeo 2003D [31] and Cloisite5, Cloisite20 and Cloisite116 clays [32-34].

\begin{tabular}{lllll}
\hline Physical properties & Clo5 & Clo20 & Clo116 & PLA Ingeo 2003D \\
\hline Moisture $(\%)$ & $<3$ & $<3$ & $8-13$ & - \\
Typical dry particle size $\left(\mu \mathrm{m}, \mathrm{d}_{50}\right)$ & $<40$ & $<10$ & $<15$ & - \\
Density $\left(\mathrm{g} / \mathrm{cm}^{3}\right)$ & 1.77 & 1.77 & 2.80 & 1.25 \\
X-ray results $\left(\mathrm{nm}, \mathrm{d}_{001}\right)$ & 3.27 & 3.16 & 1.25 & - \\
\hline
\end{tabular}

A masterbatch containing $15 \mathrm{wt} \%$ clay and $85 \mathrm{wt} \%$ Ingeo 2003D was first prepared by melt compounding. Prior to use the clay samples and the Ingeo resin were dried for at least 4 hours at $80^{\circ} \mathrm{C}$ in an oven. A Coperion's ZSK 18 twin-screw extruder (with $18 \mathrm{~mm}$ screw diameter and a L/D ratio of 40) equipped with a sharp-shearing extruder screw was employed for the preparation of the masterbatch. The screw speed was set at $300 \mathrm{rpm}$, the output set to $2 \mathrm{~kg} /$ hour, and the processing temperatures were ranged from $180^{\circ} \mathrm{C}$ to $200^{\circ} \mathrm{C}$. The clay material was added via the side feeder of the extruder (screw speed was set at $60 \mathrm{rpm}$ ). Subsequently, the masterbatches were dried for 4 hours at $80^{\circ} \mathrm{C}$. PLA/clay composite filaments were produced by diluting the masterbatch with neat PLA into the desired compositions. The filament was wound onto a spool as it was being extruded. The average filament diameter was $1.75 \mathrm{~mm}$. Table 2 lists the compositions of the PLA/clay filaments investigated.

Table 2: Composition of the PLA/clay filaments investigated.

\begin{tabular}{lllll}
\hline Clay type & \multicolumn{4}{c}{ Clay content in PLA } \\
\hline & $\mathrm{wt} \%$ & $\mathrm{vol} \%$ & $\mathrm{wt} \%$ & $\mathrm{vol} \%$ \\
\cline { 2 - 5 } Clo5 & 1 & 0.45 & 5 & 2.3 \\
Clo20 & 1 & 0.45 & 5 & 2.3 \\
Clo116 & 1 & 0.45 & - & - \\
\hline
\end{tabular}




\subsection{Fabrication of $3 D$ printed PLA/clay composite specimens}

CAD models of dumbbell specimens for tensile tests (Fig. 1a) and rectangular specimens for flexural (Fig. 1b) tests were designed following the ASTM D638-10 Type IV and ISO 178:2003 respectively. Four circular pads (of $0.5 \mathrm{~mm}$ thickness and $10 \mathrm{~mm}$ diameter) were added in the corners of the specimens (Fig. 1c) to prevent warping during printing. These pads were removed mechanically after the printing process was completed. An open-source RepRap Huxley 3D printer was fed with the PLA and PLA/clay filaments to fabricate the specimens. Slic3r software was used for slicing the CAD models and generating the printing tool paths (g-code). The 3D printer was controlled by Printrun (Pronterface) software. Both Slic3r and Printrun are free and opensource software, available online. All specimens were printed with identical printing parameters (Table 3) and with their smallest dimension (thickness) perpendicular to the printing platform, as depicted in Fig. 1c. The printing tool paths in Fig. 1c represent the rectilinear cross-hatched infill orientation employed in the printing process. These printing parameters were determined after a preliminary optimisation process, using neat PLA. Masking tape (3M Scotch blue tape) was applied on the printing platform prior to the printing process, in order to provide sufficient adhesion of the extruded material (first layer) onto the surface of the platform.

Table 3: Printing parameters used.

\begin{tabular}{ll}
\hline Printing Parameters & Values \\
\hline Nozzle temperature $\left({ }^{\circ} \mathrm{C}\right)$ & 200 \\
Nozzle diameter $(\mathrm{mm})$ & 0.5 \\
Printing speed $(\mathrm{mm} / \mathrm{s})$ & 60 \\
Infill orientation & rectilinear, cross-hatched \\
Layer thickness $(\mathrm{mm})$ & 0.3 \\
Infill density $(\%)$ & 100 \\
Perimeter & 1 \\
\hline
\end{tabular}
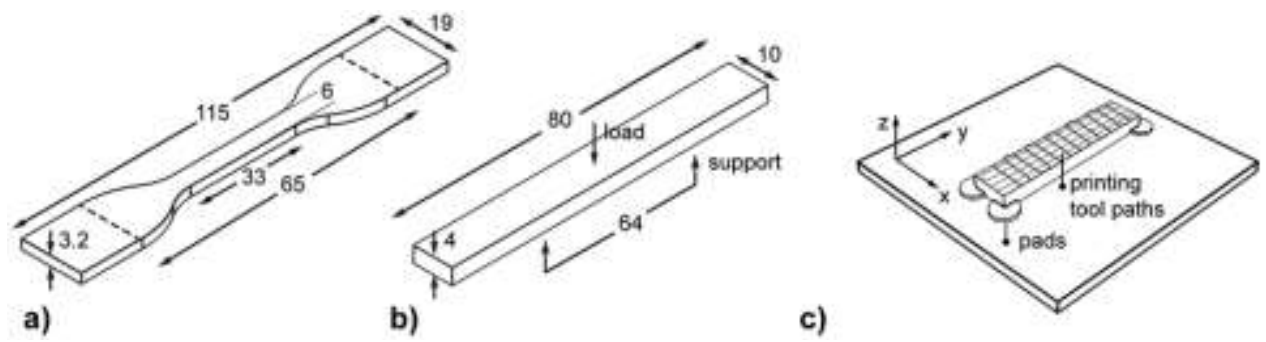

Fig. 1. Schematics of the a) ASTM D638-10 Type IV dumbbell specimen, b) ISO 178:2003 rectangular specimen and c) circular pads added in the corners of the specimens to prevent warping during printing. All noted dimensions are in $\mathrm{mm}$.

\subsection{Characterisation of PLA/clay composites}

Tensile and flexural tests were performed on a Tinius Olsen $\mathrm{H} 25 \mathrm{KS}$ universal testing machine, with $25 \mathrm{kN}$ load capacity, following the ASTM D638-10 Type IV and ISO 178:2003 respectively. Five specimens were printed and tested for each sample per test. Prior to tensile testing, the dumbbell specimens were secured between a clamped and a moving crosshead grip, with an initial distance of $65 \mathrm{~mm}$ (Fig. 1a). A direct contact extensometer (with $25 \mathrm{~mm}$ gauge length) was employed for recording the extension along the direction of the applied load. Tensile tests were run at a crosshead speed of $5 \mathrm{~mm} / \mathrm{min}$, until fracture occurred. Flexural tests (under three-point bending configuration) were carried out with a span length (distance between two supports) of 64mm, as shown in Fig. 1b. The specimens were placed symmetrically on the supports and force was applied at midspan. Flexural tests were performed with a crosshead speed of $2 \mathrm{~mm} / \mathrm{min}$, until fracture occurred. The forceextension/displacement data were recorded through the QMAT 5.46 S-series software. The fracture surface of the specimens was investigated using a Hitachi S-4300 field-emission scanning electron microscope (FESEM), 
operating at $5 \mathrm{kV}$. Prior to observation, all specimens were sputter-coated with gold.

The porosity $\mathrm{P}$ of the printed specimens was determined [18] from Eq.1:

$P=\frac{V_{t}-V_{a}}{V_{t}} \%$

where $V_{t}$ is the volume of the printed parts and $V_{a}$ the actual volume of the solid (PLA+clay). Regular shaped pieces were cut off from the gauge area of the printed dumbbell specimens and $\mathrm{V}_{\mathrm{t}}$ was calculated based on the dimensions of each cut piece. The mass $(\mathrm{m})$ of each cut piece was measured utilising a precision balance (Mettler AJ 150), and $V_{\mathrm{a}}$ was then derived employing Eq.2:

$V_{a}=\frac{m * \text { clay content } w t \%}{\rho_{\text {clay }}}+\frac{m * P L A \text { content } w t \%}{\rho_{P L A}}$

where $\rho_{\text {clay }}$ and $\rho_{\text {PLA }}$ are the densities of the clay and the PLA respectively (Table 1). The reported porosity for each sample represents the average porosity from five specimens.

\section{Results and discussion}

\subsection{Mechanical behaviour of the printed PLA/clay composites}

Typical stress-strain curves of the printed samples, obtained from the tensile tests are presented in Fig. 2. All printed samples exhibited an initial linear elastic deformation. After that, the samples behaved differently. The neat PLA and the composite samples containing $1 \mathrm{wt} \%$ organoclay (Clo5 and Clo20) then yielded with increasing load and reached to a maximum tensile stress prior to fracture (Fig. 2a), while the 1 wt\% natural clay (Clo116) sample fractured before yielding (Fig. 2a). The $5 \mathrm{wt} \%$ organoclay samples (Fig. 2b) also exhibited little plastic deformation before fracture. These results show that the clay content and type have a significant effect on the mechanical behaviour of the printed composites. Fig. 3 gives the digital images showing the typical fracture patterns of both printed neat PLA (Fig. 3a) and PLA/clay composite (Fig. 3b) samples. A brittle fracture is clearly indicated with little overall plastic deformation. This fracture character is consistent with the stress-strain behaviour shown in Fig. 2.

The measured modulus of elasticity, ultimate tensile strength, and percent elongation at break of the printed composites are summarised in Table 4. The measured properties of the composites were compared to that of the neat PLA and reported as percent relative difference (\% R.D.) in Table 4. The ultimate tensile strength recorded for the $5 \mathrm{wt} \%$ clay samples and the $1 \mathrm{wt} \%$ Clo1 16 sample corresponds to their fracture stress. The average values listed in Table 4 were calculated from five specimens. A One-way Analysis of Variance (ANOVA) and subsequent post-hoc Tukey comparisons were performed using SPSS Statistics software, in order to evaluate the effect of the composition of the filament (clay type and content) on the mechanical properties of the printed samples (Table 4). An alpha level (significance level) of 0.05 was used for all statistical tests[19]. The p-values obtained from post-hoc Tukey comparisons are listed in Table 4.
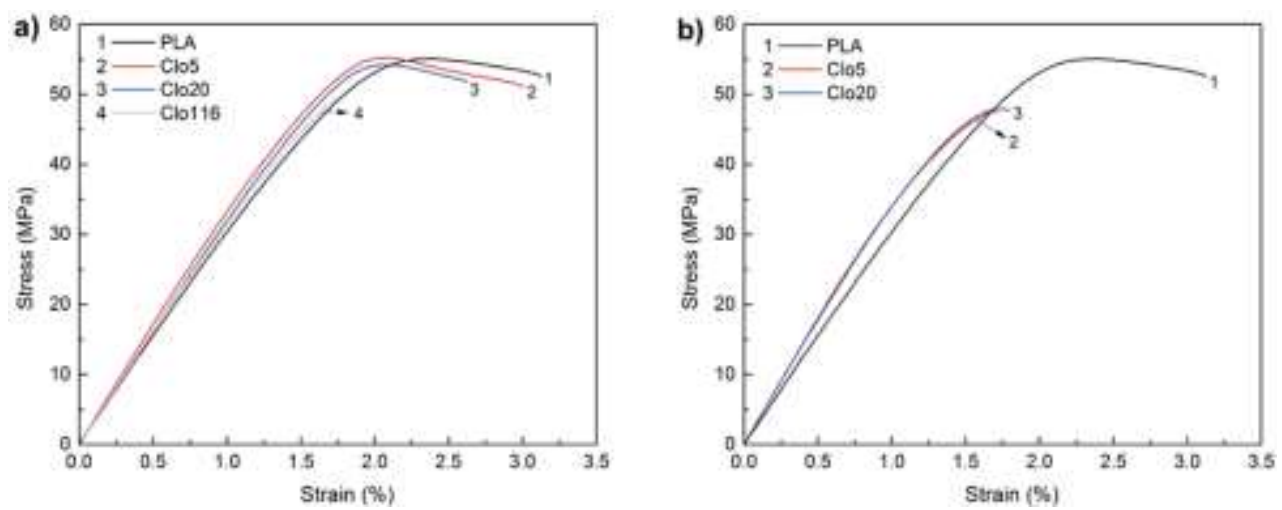
Fig. 2. Typical tensile stress-strain curves of 3D printed neat PLA and PLA/clay samples for clay content of a) $1 \mathrm{wt} \%$, and b) $5 \mathrm{wt} \%$.
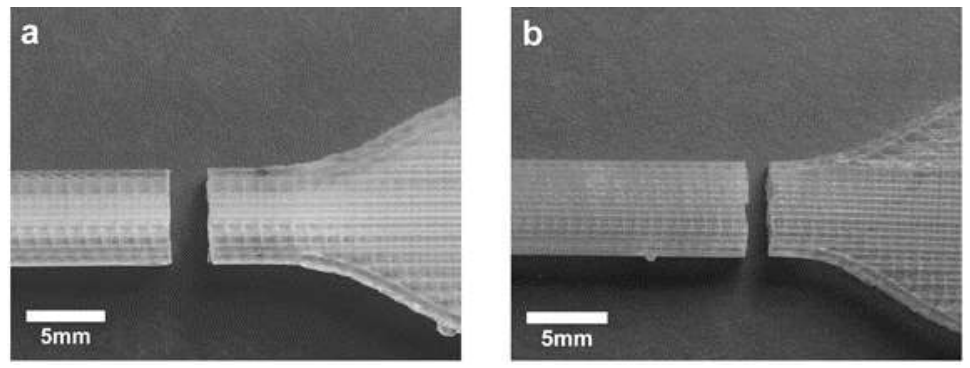

Fig. 3. Digital images of 3D printed a) neat PLA and b) PLA/clay specimens, showing the through-thickness fracture after tensile test.

Table 4: Tensile properties and porosity of the printed samples and results of Tukey post-hoc comparisons (p-value) ${ }^{1}$.

\begin{tabular}{lllllllllll}
\hline Composition & $\begin{array}{l}\text { Modulus of } \\
\text { elasticity } \\
(\mathrm{GPa})\end{array}$ & $\begin{array}{l}\% \\
\text { R.D. }\end{array}$ & $\mathrm{p}$ & $\begin{array}{l}\text { Tensile } \\
\text { strength } \\
(\mathrm{MPa})\end{array}$ & $\begin{array}{l}\% \\
\text { R.D. }\end{array}$ & $\mathrm{p}$ & $\begin{array}{l}\text { Elongation } \\
\text { at break (\%) }\end{array}$ & $\begin{array}{l}\% \\
\text { R.D. }\end{array}$ & $\mathrm{p}$ & Porosity (\%) \\
\hline PLA & $3.27 \pm 0.08$ & - & - & $55.58 \pm 1.2$ & - & - & $2.87 \pm 0.58$ & - & - & $8.92 \pm 0.38$ \\
$1 \mathrm{wt} \%$ Clo5 & $3.5 \pm 0.06$ & +7.0 & 0.007 & $54.41 \pm 1.13$ & -2.1 & 0.971 & $2.74 \pm 0.62$ & -4.5 & 0.994 & $8.69 \pm 1.13$ \\
$5 \mathrm{wt} \%$ Clo5 & $3.6 \pm 0.09$ & +10.0 & 0.000 & $47.11 \pm 2.37$ & -15.2 & 0.000 & $1.7 \pm 0.13$ & -40.8 & 0.001 & $10.77 \pm 2.66$ \\
$1 \mathrm{wt} \%$ Clo20 & $3.33 \pm 0.09$ & +1.8 & 0.887 & $54.13 \pm 1.75$ & -2.6 & 0.929 & $2.58 \pm 0.11$ & -10.1 & 0.825 & $8.64 \pm 2.10$ \\
$5 \mathrm{wt} \%$ Clo20 & $3.56 \pm 0.12$ & +8.9 & 0.001 & $46.12 \pm 4.10$ & -17.1 & 0.000 & $1.71 \pm 0.31$ & -40.4 & 0.001 & $10.52 \pm 1.85$ \\
$1 \mathrm{wt} \%$ Clo116 & $3.29 \pm 0.05$ & +0.6 & 1.000 & $46.73 \pm 2.55$ & -15.9 & 0.000 & $1.61 \pm 0.16$ & -43.9 & 0.000 & $7.05 \pm 0.98$ \\
\hline
\end{tabular}

${ }^{1} \mathrm{p}$ value stands for the comparison between the properties of neat PLA and each PLA/clay composition.

Each p-value represents the results of the comparison of the properties between neat PLA and the corresponding composition. P-values were compared with the alpha level to determine whether or not the observed differences were statistically significant. If the $p$-value is less than or equal to the alpha ( $\leq \leq 05)$, then the observed differences are considered as statistically significant]. ANOVA results showed that there was a statistically significant effect of the composition of the filament on the tensile strength [calculated F-test statistic of $\mathrm{F}(5,24)=17.031, \mathrm{p}=0.000]$, the percent elongation at break $[\mathrm{F}(5,24)=11.707, \mathrm{p}=0.000]$ and the modulus of elasticity $[\mathrm{F}(5,24)=12.772, \mathrm{p}=0.000]$ of the printed samples. In detail, there was no statistically significant difference between the tensile strength and percent elongation at break of the composite samples with $1 \mathrm{wt} \%$ organoclay (Clo5 and Clo20) and that of neat PLA. However, $1 \mathrm{wt} \%$ natural clay (Clo116) and $5 \mathrm{wt} \%$ organoclay samples exhibited a statistically significant reduction in both the tensile strength and percent elongation at break (e.g. for Clo5 clay, a reduction of $15.2 \%$ and $40.8 \%$ respectively) compared to that of neat PLA (Table 4). Therefore, the results in Table 4 indicate that adding $1 \mathrm{wt} \%$ of organoclay (Clo5 or Clo20) altered neither the tensile strength nor the ductility of the PLA matrix. Increasing the organoclay content to $5 \mathrm{wt} \%$ though, resulted in a significant reduction in the ductility and the tensile strength of the composites.

Data in Table 4 show all composite samples exhibited higher modulus of elasticity compared to that of neat PLA. ANOVA and post-hoc comparisons confirmed that the observed increase in the modulus of elasticity (Table 4) was statistically significant for the Clo5 clay samples, and was more pronounced at higher clay content (e.g. $7.0 \%$ and $10.0 \%$ increase in the average modulus values for the samples with $1 \mathrm{wt} \%$ and $5 \mathrm{wt} \%$ of Clo5 in PLA respectively). A statistically significant increase in the modulus of elasticity (8.9\%, Table 4) was also observed for the sample with $5 \mathrm{wt} \%$ Clo20 clay compared to that of neat PLA. However, the observed increase in the modulus values (Table 4) for the $1 \mathrm{wt} \%$ Clo20 and 1wt\% natural clay (Clo116) was not statistically significant (Table 4). Further investigation was then carried out in order to understand the mechanism behind 
the mechanical behaviour of the printed samples.

\subsection{Mechanism of the tensile behaviour of printed composites}

\subsubsection{Microstructure and porosity}

FESEM micrographs from the fracture surface (cross-section) of printed neat PLA and $1 \mathrm{wt} \%$ Clo5 specimens after tensile testing are presented in Fig. 4. Both specimens exhibited a relatively smooth surface, due to the brittle fracture. This brittle character is again consistent with the low ductility of the printed samples observed in Fig. 2. The FESEM micrographs revealed that the cross-section (perpendicular to the loading direction) of the printed specimens is formed of consecutively stacked layers, where individual printed beads and layers were visible. It is clear that the printed specimens were inherently porous. The triangular air voids present in all specimens were due to the layering approach of the $3 \mathrm{D}$ printing process.
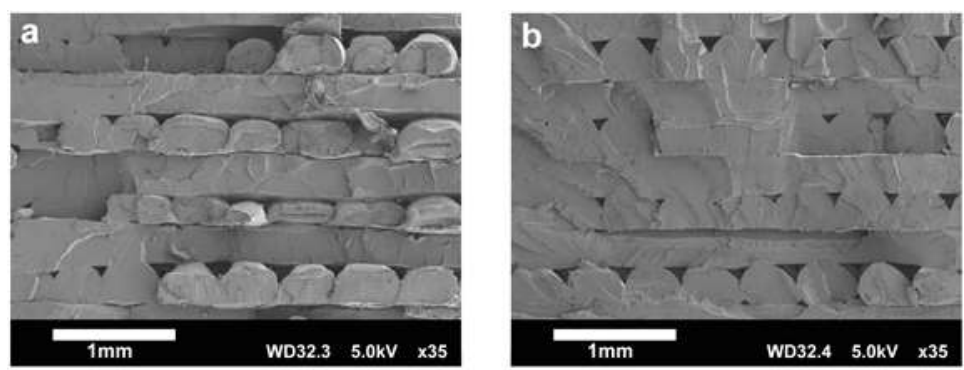

Fig. 4. FESEM micrographs of the fracture surface of 3D printed dumbbell specimens of a) neat PLA and b) PLA/1 wt $\%$ Clo5 composite specimens.

The overall porosity of the printed PLA/clay specimens determined using Eq. 1 is presented in Fig. 5. It can be seen that the lowest measured average porosity is recorded for the composite sample with $1 \mathrm{wt} \%$ natural clay (Clo116). The $5 \mathrm{wt} \%$ organoclay samples appeared to have the highest average porosity values. All tested clay samples showed higher standard deviation values than that of neat PLA samples. Taking into account the standard deviations, it could be considered that all samples containing Clo5 and Clo20 clay exhibited similar porosity to that of neat PLA. Pores are generally expected to have a negative impact on the load bearing behaviour of materials. However, it is noted that Clo116 sample exhibited the lowest performance in terms of tensile behaviour (Fig. 2, Table 4) of all composite samples, whereas its measured porosity was the lowest among all clays. This suggests that the overall porosity of the printed samples did not seem to be the major reason accounting for the observed differences in the mechanical properties among the 3D printed PLA/clay composites.

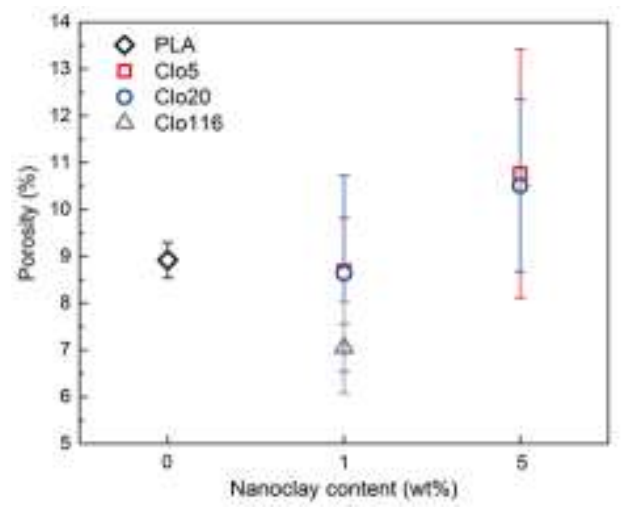

Fig. 5. Porosity of the 3D printed PLA/clay composites and neat PLA samples.

\subsubsection{Dispersion of clay platelets}


In their powder form, the raw clays (organomodified or natural) consisted of large aggregates of stacked aluminosilicate platelets, as shown in Fig. 6a, which gives an FESEM micrograph of typical organomodified clay powder, before dispersion in the PLA matrix. Upon the application of high shear forces during the melt processing of the PLA/clay systems (in the fabrication of the feedstock filaments), the aggregated clay platelets were delaminated into smaller stacks of platelets as shown in Fig.6b. The quality of the clay dispersion depended on the clay type and the shear forces.

Conventional foil tests were conducted to help assess macroscopically the overall dispersion of the clay particles in PLA and for use as a method of quality control. The test is empirical and consists of making a thin foil of thickness 800-900 $\mu \mathrm{m}$ from the polymer composite and observing its surface with the naked eye. It has been found experimentally for the PLA/nanoclay composites under study that if no defects (clay aggregates) are observed, then the material will be expected to contain a good dispersion (uniformly dispersed clay platelets), while if defects are observed, then the material will have a poor dispersion (coarse aggregates of clay). By way of illustration, Fig. 7 shows thin foils of PLA/5 wt $\%$ clay: Fig. 7a has no visible defects and showed a good dispersion of clay platelets. Conversely, Fig. $7 \mathrm{~b}$ possesses distinct defects (or aggregates) indicative of a poor nanoparticle dispersion. All PLA/clay composite specimens used in this study had the same dispersion quality as indicated in Fig. 7a. However, this test can only confirm that large clay aggregates were fractured down to small stacks of platelets but is not able to assess the size or extent of intercalation of the clay platelets. Nevertheless, it has been found to be a useful empirical method of helping to identify the presence of nanosized clay platelets. It is pointed out that the reinforcement is related not only to the overall distribution of the clay particles but also to the extent of intercalation and/or exfoliation of the clays in the polymer matrix [20].

Fig. $6 \mathrm{~b}$ is a typical TEM micrograph of $5 \mathrm{wt} \%$ organoclay in the PLA matrix presenting the main constituents of the structure. It shows a heterogeneous clay distribution, consisting of a mixture of clay agglomerates, coexisting with intercalated clay stacks, and exfoliated platelets. The large dark features in Fig. $6 \mathrm{~b}$ are clay agglomerates and the regions in between them show a uniform dispersion of exfoliated nanosized platelets. These appear in the micrograph as thin dark linear features of approximately $100 \mathrm{~nm}$ in length and $30 \mathrm{~nm}$ in thickness. The dispersion of platelets may be considered as providing a nanostructure within the polymer matrix.

Many of the exfoliated platelets appear to be in contact with one another and form a network, possibly with interactive bonding with the polymer matrix. Providing the stacks of the platelets are thin enough, uniformly dispersed, well bonded to the matrix and sufficiently close together, this will enable substantial reinforcement of the polymer matrix through a load-transfer mechanism and molecular interaction [20]. The interaction will involve intercalation of the polymer into the clay and may be quantified by the average number of platelets per clay stack: the greater the intercalation, the smaller the number of platelets per stack. The effect of intercalation on the mechanical behaviour of the composites is investigated in the following section.
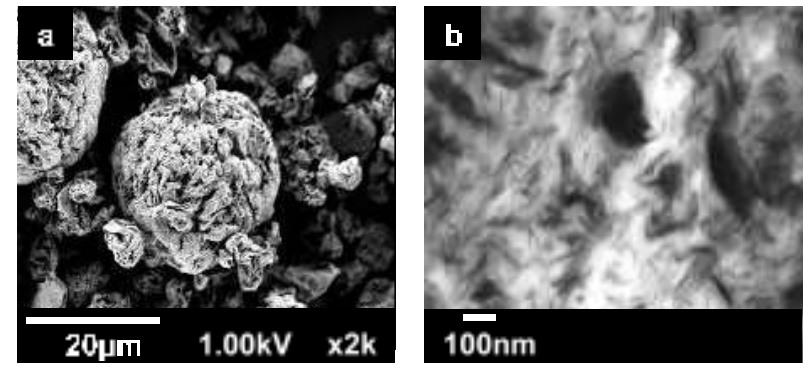

Fig. 6. a) Typical SEM micrograph of organomodified clay powder, and b) typical TEM micrograph showing the dispersion of clay platelets in the polymer matrix. 


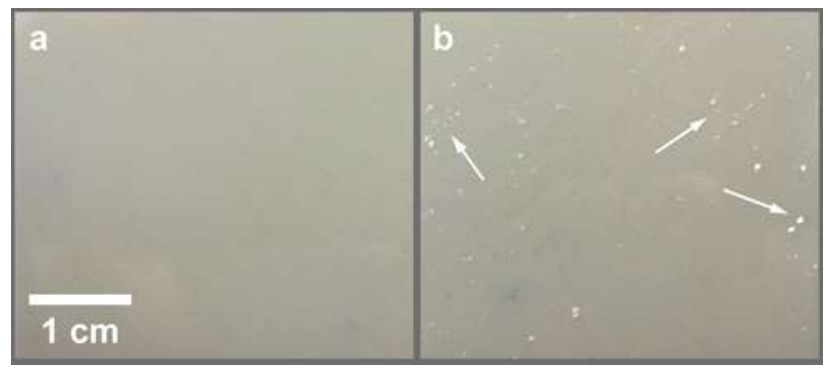

Fig. 7. Optical images of foil test results of $5 \mathrm{wt} \%$ clay in PLA with a) uniform clay particle dispersion and b) non-uniform clay particle dispersion.

\subsubsection{Prediction of modulus of elasticity of the PLA/clay composites}

PLA/clay composites were considered as two-component systems [Cloisite clay platelets as the dispersed phase (filler) and PLA as the matrix]. In the case of organoclays (Clo5 and Clo20), the organic modifiers were not treated as a separate phase. The properties of each component were considered the same as those of the raw materials, before blending (Table 1). Only the density of the high modulus clay platelets is considered in the determination of the volume fraction of the clay phase (Table 2). In this case, the density of the natural clay Clo1 $16\left(2.8 \mathrm{~g} / \mathrm{cm}^{3}\right)$ is used. In addition, both clays and matrix were considered to be linearly elastic, isotropic and well bonded to each other before yield. Both Einstein's theory of viscosity [21,22] and Halpin-Tsai's [23] model were applied to calculate the modulus of elasticity of the PLA/clay composites.

Einstein's theory is generally utilised for predicting the modulus of elasticity of particulate composites [24] at low filler content (typically less than 5 vol\% [25]), and assuming perfect adhesion between the filler and the matrix, it may be expressed as:

$E_{c} / E_{m}=1+2.5 V_{f}$

where $E_{c}$ and $E_{m}$ are the modulus of elasticity of the composite and the matrix respectively, and $\mathrm{V}_{\mathrm{f}}$ is the volume fraction of the filler in the composite. In the present system of PLA/clay, $\mathrm{E}_{\mathrm{m}}$ was taken as 3.27 GPa, which corresponds to the measured modulus of neat PLA (Table 4).

The calculated normalised modulus of elasticity $\mathrm{E}_{\mathrm{c}} / \mathrm{E}_{\mathrm{m}}$ from Einstein's theory is presented in Fig. 8 as a function of clay content and shows the expected linear relationship. However, the experimental results for both the PLA/Clo5 and PLA/Clo20 are much higher than Einstein's predicted values, which implies other factors play a role.

The Halpin-Tsai model provides an alternative approach that incorporates the geometry and elastic modulus of the filler as well as its content and has been used to predict the stiffness of polymer composites with fibre or disk-like fillers, including polymer/nanoclay composites [26,27]. The normalised elastic modulus can be written in the form:

$\frac{E_{C}}{E_{m}}=\frac{1+\zeta \eta V_{f}}{1-\eta V_{f}}$

where $E_{c}$ and $E_{m}$ are the modulus of elasticity of the composite and the matrix respectively and $V_{f}$ is the volume fraction of the filler. In this equation, $\zeta$ is an adjustable shape parameter that depends on the geometry of the filler and $\eta$ is given by:

$\eta=\frac{\frac{E_{f}}{E_{m}}-1}{\frac{E_{f}}{E_{m}}+\zeta}$

where $\mathrm{E}_{\mathrm{f}}$ is the modulus of elasticity of the filler.

This model is applied to the current composites under study in which the controlling filler is taken to be the 
organically modified and natural clay platelets. Fig. $6 \mathrm{~b}$ shows that the clay platelets are randomly oriented and distributed within the PLA matrix. However, in the analysis used here, all the clay platelets were assumed to be oriented along the loading direction and consequently, a longitudinal modulus was determined. The predicted results will therefore only represent the upper limit of the elastic modulus of the composite and the experimentally measured moduli should be below this limit. The platelet stacks are assumed to be disc-like and for a longitudinal modulus, the shape parameter $\zeta$ can be taken to be [26]:

$$
\zeta=21 / t
$$

where 1 and $t$ are the length and thickness of the platelet respectively. Equations (4) to (6) link the stiffness of the composite to the aspect ratio of the platelets. This enables a quantified relationship with the fineness of the dispersion and extent of exfoliation to be determined. The gradual exfoliation of a platelet stack reduces its thickness $(t)$ and hence gives a larger aspect ratio $(1 / t)$.

The average length (1) of the clay platelets was estimated using TEM observations to be $100 \mathrm{~nm}$, while the average thickness of the clay stacks $\left(\mathrm{t}_{\text {clay }}\right)$ was calculated using the following equation:

$$
\mathrm{t}_{\text {clay }}=(\mathrm{n}-1) \mathrm{d}_{001}+\mathrm{t}_{\text {platelet }}
$$

where $\mathrm{n}$ is the number of platelets per clay stack, $\mathrm{d}_{001}$ is the $\mathrm{d}$-spacing within the clay stack and $\mathrm{t}_{\text {platele }}$ is the thickness of a single clay platelet taken equal to $0.94 \mathrm{~nm}[26,27]$. The $\mathrm{d}$-spacing values $\left(\mathrm{d}_{001}\right)$ of the as-received clays were used in the calculations and the corresponding values for all three clays are listed in Table 1.

Only the high modulus clay platelets were considered as a reinforcing phase in the current PLA/clay system. The effective modulus of the clay platelets was taken as the modulus of the filler $\mathrm{E}_{\mathrm{f}}$ and determined by the rule of mixtures:

$$
E_{f}=E_{M M T} V_{\text {clay }}+E_{\text {gallery }} V_{\text {gallery }}
$$

where $\mathrm{E}_{\mathrm{MMT}}$ is the modulus of the pure clay (montmorillonite) platelets taken as having a magnitude of $178 \mathrm{GPa}$ $[25,27,28], E_{\text {gallery }}$ is the modulus of the organic modifiers within the galleries of the clay platelets for which $E_{\text {gallery }}<<\mathrm{E}_{\mathrm{MMT}}$ in the case of organoclay and $\mathrm{E}_{\text {gallery }}=0$ for natural clay. $\mathrm{V}_{\text {clay }}$ and $\mathrm{V}_{\text {gallery }}$ are the volume fractions of the clay platelets and the galleries respectively. Hence:

$$
E_{f}=E_{M M T} \times \frac{n t_{\text {platelet }}}{t_{\text {clay }}}=178 \times \frac{0.94 n}{(n-1) d_{001}+t_{\text {platelet }}}=178 \times \frac{0.94 n}{(n-1) d_{001}+0.94}
$$

As obtained from the Halpin-Tsai model, the calculated normalised (longitudinal) modulus of elasticity of the composites $\mathrm{E}_{\mathrm{c}} / \mathrm{E}_{\mathrm{m}}$ is plotted against the clay content in Fig. 9a and Fig. 9b. In general, the calculated ratio $\mathrm{E}_{\mathrm{c}} / \mathrm{E}_{\mathrm{m}}$ of the PLA/clay composites increased linearly with clay content. However, the efficiency of the reinforcement (as reflected by the gradient of the calculated trend lines) reduced significantly with increasing number of platelets per clay stack (reduced extent of clay intercalation). For example, in Fig. 9a, the gradient of the $n=2$ predicted line (high extent of intercalation/exfoliation) was approximately 5 times greater than the gradient of the $n=13$ line, suggesting that the extent of clay intercalation greatly affected the performance of the composites.

The measured modulus values are also shown in Fig. 9 in order to compare the effect of the clay dispersion. It is noted that the measured $\mathrm{E}_{\mathrm{c}} / \mathrm{E}_{\mathrm{m}}$ value for $1 \mathrm{wt} \%$ Clo5 organoclay (Fig. 9a) was close to the predicted trend line of $n=2$, while the $E_{c} / E_{m}$ value for the $5 \mathrm{wt} \%$ sample was close to the line of $n=13$. This indicates that the $1 \mathrm{wt} \%$ Clo5 clay sample exhibited on average a higher extent of clay intercalation than that of the $5 \mathrm{wt} \%$ Clo5 sample. As a result, the $5 \mathrm{wt} \%$ clay sample would have exhibited a much higher elastic modulus if the same intercalation $(n=2)$ had been achieved: an $E_{c} / E_{m}$ value of 1.36 instead of the measured value on Fig. 9a of only 1.10. The experimental results for both $1 \mathrm{wt} \% \mathrm{Clo} 20$ and $5 \mathrm{wt} \%$ Clo20 (Fig. 9a) samples lie on the calculated trend line of $n=16$, implying that the Clo20 samples have a lower average extent of clay intercalation than that of the Clo5 samples. This is consistent with the inferior mechanical performance of Clo20 relative to that of Clo5. The results indicate that increasing the extent of intercalation is much more efficient than increasing the clay content. 
The measured ratio $E_{c} / E_{m}$ for the Clo116 natural clay sample (Fig. 9b) was consistent with a calculated line of $n=80$, which corresponds to an aspect ratio of unity and indicates no significant intercalation. This is to be expected as the Clo116 natural clay contained no organic modifier and so behaved like a conventional filler. The latter could not sufficiently improve the stiffness of the composite at the current $1 \mathrm{wt} \%$ content (Fig. 8).

Fig. 10 plots the calculated $\mathrm{E}_{\mathrm{c}} / \mathrm{E}_{\mathrm{m}}$ values of the PLA/clay composites and the effective modulus of the clay particles as a function of the number of platelets per stack. It shows that the effective modulus of clay particles and the stiffness of PLA/clay composite of all clay types increases as the number of platelets per stack decreases. The stiffness of the composite increases with increased effective modulus of the clays but becomes less sensitive to the filler modulus when the number of clay platelets per stack increase, suggesting the number of platelets per clay stack (extent of intercalation) plays a dominant effect on the moduli of the polymer/clay composites. The highest predicted stiffness is exhibited by the natural clay Clo116 due to its high effective modulus, which results from the fact that it has the lowest gallery volume. However, its experimentally measured stiffness (Fig. 9b) is much lower than the organically modified clays (Clo5 and Clo20). The reason for the discrepancy and the low experimentally measured values of Clo116 is due to the lack of both interaction and subsequent exfoliation in this clay. In particular, Clo116 has a much larger number of platelets per stack $(n=80)$ compared with Clo5 and Clo20, which only have $\mathrm{n}$ values between 2 and 16 .

Fig. 9 and Table 1 show that the nanoclays (Clo5 and Clo20) provide higher reinforcement than the natural Clo1 16 clay. It is noted that Clo5 has the largest d-spacing (Table 1) and hence gallery volume, which is expected to promote the intercalation of the clay platelets, their dispersibility and exfoliation in the PLA matrix [20,29]. As a result, PLA/Clo5 shows the highest mechanical properties amongst all of the composites, as given in Table 4.

Further improvement of the modulus of elasticity with the natural clay may be achieved through higher clay content (Fig. 9). However, as shown in Fig. 2a, the 1 wt\% Clo116 sample fractured before the matrix yielded, possibly due to insufficient adhesion between the clay and PLA matrix, resulting in reduced ductility and fracture strength. In practice, the process of incorporating $5 \mathrm{wt} \%$ Clo116 in PLA to achieve a uniform clay distribution was found to be difficult.

Although the Halpin-Tsai model applies mainly to elastic behaviour, it can provide useful insights into tensile strength. Specifically, the Halpin-Tsai model indicated that less intercalation took place in the printed $5 \mathrm{wt} \%$ organoclay and the $1 \mathrm{wt} \%$ Clo 116 (natural clay) samples. This reduction in intercalation will affect the underlying structure of the composite by increasing the amount of unexfoliated agglomerates and decreasing the clay-matrix interfacial contact and adhesion. These effects are expected to lead to the observed fall in tensile strength and ductility (Table 4). It is pointed out that the observed evolution of tensile strength of the PLA/clay composites with increased clay content is similar to that observed in compression-moulded PLA/clay composites reported in literature $[10,30]$.

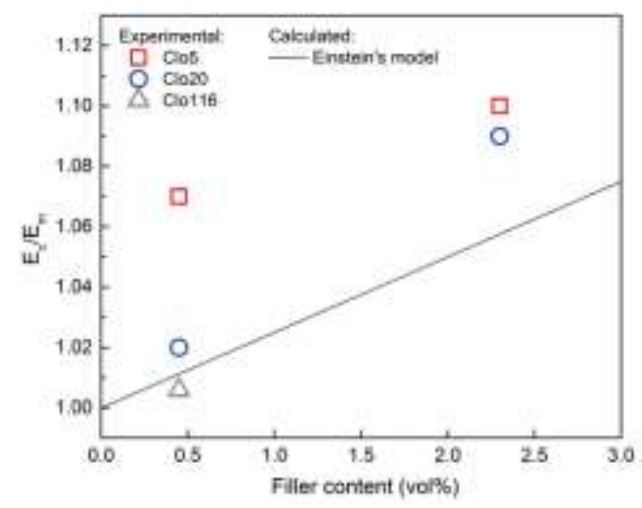

Fig. 8. Normalised modulus of elasticity $\left(\mathrm{E}_{\mathrm{c}} / \mathrm{E}_{\mathrm{m}}\right)$ for the PLA/clay composites, as determined from both experimental data and calculations based on the Einstein's theory. 

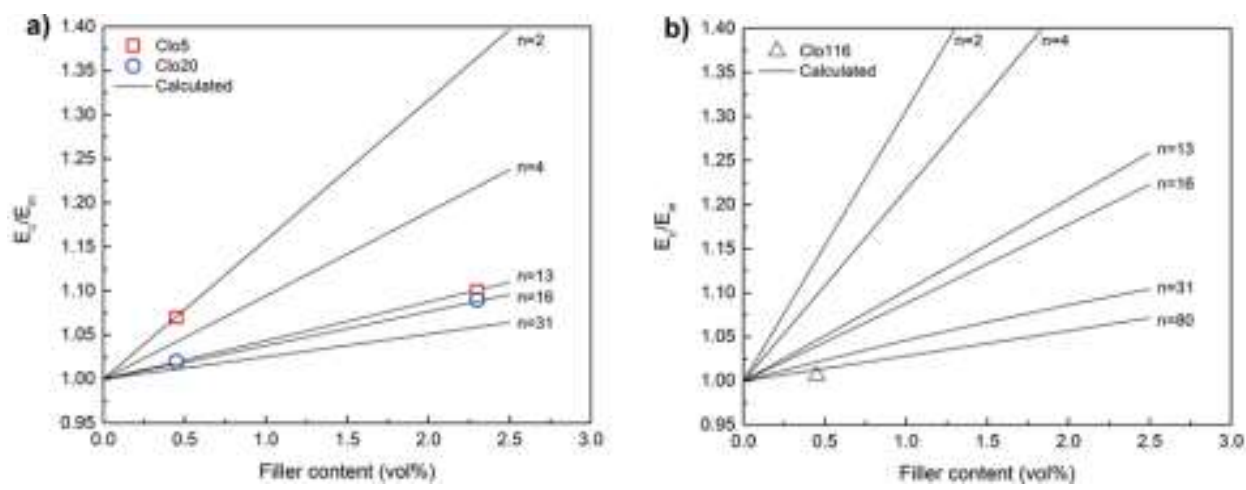

Fig. 9. Normalised modulus of elasticity $\left(\mathrm{E}_{\mathrm{c}} / \mathrm{E}_{\mathrm{m}}\right)$ for the PLA/clay composites, as determined from both experimental measurements and theoretical calculations based on the Halpin-Tsai model for a) Clo5 and Clo20 and b) Clo116 composite samples.

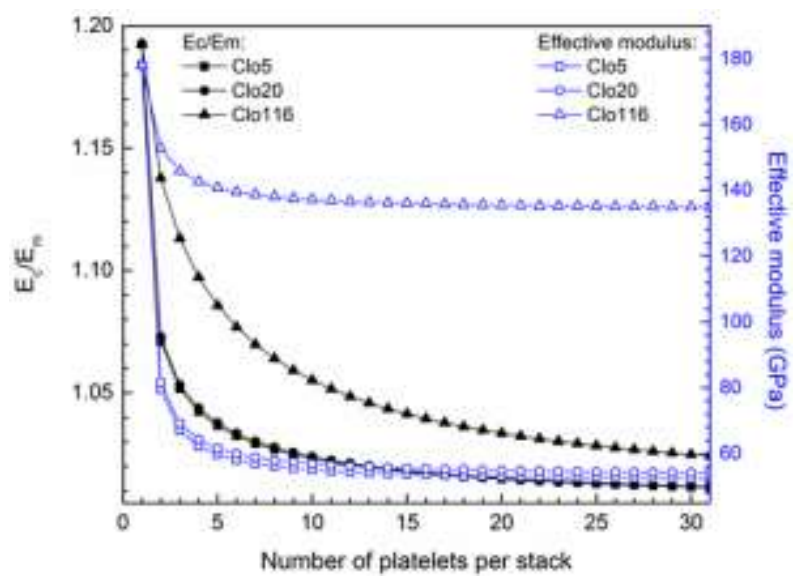

Fig.10. Influence of the effective modulus $\mathrm{E}_{\mathrm{f}}$ of the clay particles on the calculated normalised modulus of elasticity $\left(\mathrm{E}_{\mathrm{c}} / \mathrm{E}_{\mathrm{m}}\right)$ of the PLA/clay composites at $1 \mathrm{wt} \%$ clay content.

\subsection{Flexural properties}

Typical flexural stress-deflection curves of PLA/clay samples, obtained by three-point bending tests, are illustrated Fig. 11. ANOVA results showed that there was a statistically significant effect of the composition of the filament on the flexural modulus $[\mathrm{F}(4,20)=6.162, \mathrm{p}=0.002]$, the flexural strength $[\mathrm{F}(4,20)=5.679, \mathrm{p}=0.003]$ and the ductility $[\mathrm{F}(4,20)=7.857, \mathrm{p}=0.001]$ of the printed samples. The results follow a similar trend to that observed in the tensile tests: significantly increased flexural modulus and reduced strength and ductility for the $5 \mathrm{wt} \%$ samples, but no significant difference neither in the strength nor the ductility for the $1 \mathrm{wt} \%$ samples. Tukey post-hoc comparisons (Table 5) indicated that the flexural modulus exhibited a statistically significant increase of $13.9 \%$ only for the $5 \mathrm{wt} \%$ Clo5 sample compared to the modulus of neat PLA. Compared with the neat PLA sample, there is a $21.1 \%$ reduction in the flexural strength for the $5 \mathrm{wt} \%$ clay samples, while no significant difference was observed for the $1 \mathrm{wt} \% \mathrm{Clo5}$ sample. It is noted that the increase of elastic modulus of $1 \mathrm{wt} \%$ Clo5 was found to be statistically significant in the case of tensile tests $(\mathrm{p}=0.007)$ but insignificant in the case of flexural tests $(\mathrm{p}=0.632)$. This could be attributed to the larger standard deviation $( \pm 0.19 \mathrm{GPa})$ of the flexural modulus compared to that of the tensile modulus ( $\pm 0.06 \mathrm{GPa}$ ). Taking into account that flexural tests are surface-sensitive, the inherent surface roughness of the printed specimens could give rise to the high standard deviation of the test results. 
Table 5: Flexural properties of the printed samples and results of Tukey post-hoc comparisons (p-value $)^{2}$

\begin{tabular}{llllllllll}
\hline Composition & $\begin{array}{l}\text { Flexural } \\
\text { modulus } \\
(\mathrm{GPa})\end{array}$ & $\begin{array}{l}\% \\
\text { R.D. }\end{array}$ & $\mathrm{p}$ & $\begin{array}{l}\text { Flexural } \\
\text { strength } \\
(\mathrm{MPa})\end{array}$ & $\%$ R.D. & $\mathrm{p}$ & $\begin{array}{l}\text { Flexural } \\
\text { strain at } \\
\text { break }(\%)\end{array}$ & $\%$ R.D. & $\mathrm{p}$ \\
\hline PLA & $3.17 \pm 0.17$ & - & & $89.98 \pm 8.56$ & - & & $3.54 \pm 0.37$ & - \\
$1 \mathrm{wt} \%$ Clo5 & $3.36 \pm 0.19$ & +6.0 & 0.632 & $84.54 \pm 9.52$ & -6.0 & 0.905 & $3.02 \pm 0.44$ & -14.7 & 0.299 \\
$5 \mathrm{wt} \%$ Clo5 & $3.61 \pm 0.15$ & +13.9 & 0.043 & $70.96 \pm 4.21$ & -21.1 & 0.046 & $2.3 \pm 0.2$ & -35.0 & 0.001 \\
\hline
\end{tabular}

${ }^{2} \mathrm{p}$-value stands for the comparison between the properties of neat PLA and each PLA/clay composition.

In summary, Einstein's composite theory did not hold for the PLA/organoclay composites but the experimental results were found to be consistent with the Halpin-Tsai model, which enables the prediction of their mechanical behaviour. An implication from the research is that clay intercalation is more effective as a reinforcement technique than raising the total clay content.

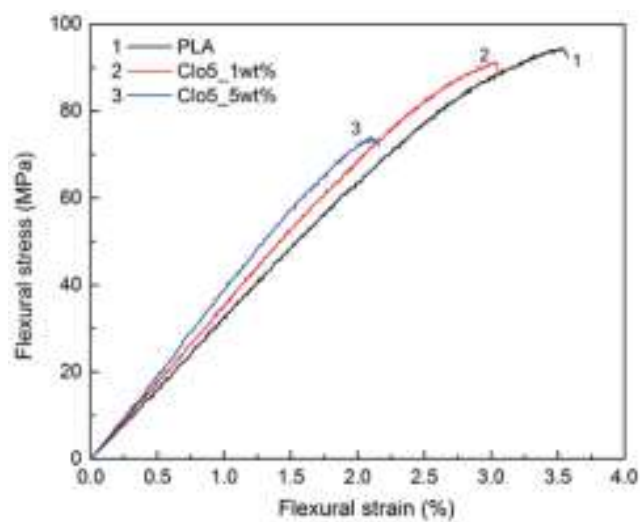

Fig.11 Typical flexural stress-strain curves of 3D printed neat PLA and PLA/clay samples.

\section{Conclusions}

PLA and PLA/clay nanocomposites were successfully printed by an open-source 3D printer based on fused filament fabrication. The porosity of the printed PLA/clay composite samples was not significantly different from that of neat PLA samples. However, the mechanical behaviour of the printed composite samples was influenced significantly by the clay content. The tensile moduli of the printed nanocomposites were increased by $7 \%$ for the $1 \mathrm{wt} \%$ and $10 \%$ for the $5 \mathrm{wt} \%$ organoclay (Clo5) samples, while the tensile strength and ductility were reduced by $15 \%$ and $41 \%$ respectively for the $5 \mathrm{wt} \%$ organoclay content and remain unchanged for the $1 \mathrm{wt} \%$ samples. The clay type also affected significantly the mechanical behaviour of the printed composite samples. For the same clay content, the samples containing organomodified clay exhibited both better modulus of elasticity and strength than the samples with natural clay, while the organoclay with the highest d-spacing value (Clo5) gave the best performance. Composite theory, which assumes good bonding and no chemical interaction between matrix and filler, was applied to explain the mechanical behaviour of the printed samples. The calculated results indicated that the upper limit for the modulus of elasticity of the nanocomposite was related to not only the clay content but also to the extent of the intercalation of the clay platelets. The latter determines the aspect ratio of the clays and the interfacial area between the clay platelets and the matrix, which is key for the efficiency of the reinforcement and consistent with the experimental observations. The natural clay had the lowest mechanical performance mainly due to an absence of intercalation. An investigation of the influence of matrix structure on composite properties is in progress.

\section{Acknowledgements}

The authors would like to thank London South Bank University for sponsoring the research. They are also 
grateful to Mr Paul Elsdon for technical assistance in the mechanical tests.

\section{References}

[1] Jones R, Haufe P, Sells E, Iravani P, Olliver V, Palmer C, et al. RepRap - the replicating rapid prototyper. Robotica 2011;187:177-91.

[2] Boparai KS, Singh R, Singh H. Development of rapid tooling using fused deposition modeling: a review. Rapid Prototyp J 2016;22:281-99.

[3] N. Turner B, Strong R, A. Gold S. A review of melt extrusion additive manufacturing processes: I. Process design and modeling. Rapid Prototyp J 2014;20:192-204.

[4] Ahn S-H, Montero M, Odell D, Roundy S, Wright PK. Anisotropic material properties of fused deposition modeling ABS. Rapid Prototyp J 2002;8:248-57.

[5] Ziemian S, Okwara M, Ziemian CW. Tensile and fatigue behavior of layered acrylonitrile butadiene styrene. Rapid Prototyp J 2015;21:270-8.

[6] Dawoud M, Taha I, Ebeid SJ. Mechanical behaviour of ABS: An experimental study using FDM and injection moulding techniques. J Manuf Process 2016;21:39-45. doi:10.1016/j.jmapro.2015.11.002.

[7] Carneiro OS, Silva AF, Gomes R. Fused deposition modeling with polypropylene. Mater Des 2015;83:768-76.

[8] Wu W, Geng P, Li G, Zhao D, Zhang H, Zhao J. Influence of Layer Thickness and Raster Angle on the Mechanical Properties of 3D-Printed PEEK and a Comparative Mechanical Study between PEEK and ABS. Materials (Basel) 2015;8:5834-46.

[9] Pirani SI, Krishnamachari P, Hashaikeh R. Optimum loading level of nanoclay in PLA nanocomposites: Impact on the mechanical properties and glass transition temperature. J Thermoplast Compos Mater 2013;27:1461-78.

[10] Kontou E, Niaounakis M, Georgiopoulos P. Comparative study of PLA nanocomposites reinforced with clay and silica nanofillers and their mixtures. J Appl Polym Sci 2011;122:1519-29.

[11] Weng Z, Wang J, Senthil T, Wu L. Mechanical and thermal properties of ABS/montmorillonite nanocomposites for fused deposition modeling 3D printing. Mater Des 2016;102:276-83.

[12] Francis V, Jain PK. Experimental investigations on fused deposition modelling of polymer-layered silicate nanocomposite. Virtual Phys Prototyp 2016:1-13.

[13] Ahmadi S, Nassiri P, Ghasemi I, Monazzam Ep MR. Acoustic Performance of 3D Printed Nanocomposite Earmuff. Glob J Health Sci 2015;8:45157.

[14] Guo Y, Chang C-C, Halada G, Cuiffo MA, Xue Y, Zuo X, et al. Engineering flame retardant biodegradable polymer nanocomposites and their application in 3D printing. Polym Degrad Stab 2017;137:205-15.

[15] Abdul Haq RH, Wahab MS, Wahid MU. Fused Deposition Modeling of PCL/HA/MMT Biocompatible Polymer Nano-composites. In: In: Öchsner A. AH (eds), editor. Mach. Join. Modif. Adv. Mater. Adv. Struct. Mater., Springer, Singapore; 2016, p. 23-32. doi:10.1007/978-981-10-10828_3.

[16] Wang X, Jiang M, Zhou Z, Gou J, Hui D. 3D printing of polymer matrix composites: A review and prospective. Compos Part B Eng 2017;110:442-58.

[17] Howard Blum. The Future of 3D Printing to 2025, Smithers Pira. 2015.

[18] Ning F, Cong W, Qiu J, Wei J, Wang S. Additive manufacturing of carbon fiber reinforced thermoplastic composites using fused deposition modeling. Compos Part B Eng 2015;80:369-78.

[19] Molugaram K, Rao GS. Hypothesis Testing. In: Kumar Molugaram, G. Shanker Rao, editors. Stat. Tech. Transp. Eng., Butterworth-Heinemann: Elsevier; 2017, p. 339-82. doi:10.1016/B978-0-12811555-8.00008-8.

[20] Olad A. Polymer/Clay Nanocomposites. In: Dr. Boreddy Reddy (Ed.), editor. Adv. Divers. Ind. Appl. Nanocomposites, InTech; 2011.

[21] Einstein A. Berichtigung zu meiner Arbeit: "Eine neue Bestimmung der Moleküldimensionen.” Ann Phys 1911;339:591-2.

[22] Einstein A. Eine neue Bestimmung der Moleküldimensionen. Ann Phys 1906;19:289-306.

[23] Halpin JC. Stiffness and Expansion Estimates for Oriented Short Fiber Composites. J Compos Mater 1969;3:732-4. 
[24] Guth E. Theory of Filler Reinforcement. J Appl Phys 1945;16:20-5.

[25] Chen B, Evans JRG, Greenwell HC, Boulet P, Coveney P V., Bowden AA, et al. A critical appraisal of polymer-clay nanocomposites. Chem Soc Rev 2008;37:568-94.

[26] Fornes, T.D. PD. Modeling properties of nylon 6/clay nanocomposites using composite theories. Polymer (Guildf) 2003;44:4993-5013.

[27] Lai S-M, Wu S-H, Lin G-G, Don T-M. Unusual mechanical properties of melt-blended poly(lactic acid) (PLA)/clay nanocomposites. Eur Polym J 2014;52:193-206.

[28] Chen B, Evans JRG. Elastic moduli of clay platelets. Scr Mater 2006;54:1581-5.

[29] Pavlidou S, Papaspyrides CD. A review on polymer-layered silicate nanocomposites. Prog Polym Sci 2008;33:1119-98. doi:10.1016/J.PROGPOLYMSCI.2008.07.008.

[30] Zaidi L, Bruzaud S, Bourmaud A, Mederic P, Kaci M, Grohens Y. Relationship between structure and rheological, mechanical and thermal properties of polylactide/Cloisite 30B nanocomposites. J Appl Polym Sci 2010;116:1357-65. doi:10.1002/app.31655.

[31] NatureWorks. Ingeo ${ }^{\mathrm{TM}}$ Biopolymer 2003D Technical Data Sheet For Fresh Food Packaging and Food Serviceware n.d.

[32] BYK-Chemie GmbH. CLOISITE-5 n.d. https://www.byk.com/en/additives/additives-by-name/cloisite5.php (accessed November 22, 2016).

[33] BYK-Chemie GmbH. CLOISITE-20 n.d. https://www.byk.com/en/additives/additives-byname/cloisite-20.php (accessed November 22, 2016).

[34] BYK-Chemie GmbH. CLOISITE-116 n.d. https://www.byk.com/en/additives/additives-byname/cloisite-116.php (accessed November 22, 2016). 